\title{
Commentary \\ Knowing who would respond to a recruitment maneuver before actually doing it - this might be a way to go
}

\author{
Ralf Kuhlen
}

HELIOS Hospital Berlin Buch, Teaching Hospital of the Charite, University Berlin, Schwanebecker Chaussee 50 - 13125 Berlin, Germany

Corresponding author: Ralf Kuhlen, ralf.kuhlen@helios-kliniken.de

Published: 31 March 2008

Critical Care 2008, 12:125 (doi:10.1186/cc6834)

This article is online at http://ccforum.com/content/12/2/125

(C) 2008 BioMed Central Ltd

See related research by Koefeld-Nielsen et al., http://ccforum.com/content/12/1/R7

\begin{abstract}
Using recruitment manoeuvres in acute lung injury remains a controversial issue because no convincing outcome data support their general use, although many physiological studies have demonstrated beneficial effects on lung compliance, end-expiratory lung volume and gas exchange. One of the reasons why physiologically meaningful observations do not translate into clear clinical benefit could be the heterogeneity of the studied patient population. In patients with consolidated lungs and only limited potential for recruitment, manoeuvres might be harmful, whereas in patients with high potential for recruitment they might be helpful. However, when those populations are mixed any signal may be lost because of counteracting effects, depending on how the patient population was mixed. We do not currently have any simple tool that may readily be applied at the bedside to assess the recruitment potential in an individual patient, which would be a sine qua non for identifying a homogeneous population in a recruitment study. Therefore, the method presented by Jacob Koefeld-Nielsen and colleagues in the previous issue of Critical Care provides us with a simple method that could be used the bedside to assess recruitment potential before the manoeuvre is applied.
\end{abstract}

In the previous issue of Critical Care, Koefeld-Nielsen and colleagues [1] provide us with interesting experimental data regarding the question of how to predict response to a recruitment manoeuvre before applying it. They conducted an animal study (lavage-induced experimental lung injury) to test the hypothesis that parameters derived from the pressurevolume (PV) loop recorded before application of the lung recruitment manoeuvre (LRM) predict the effects of the LRM on gas exchange, respiratory system compliance (Crs) and changes in end-expiratory lung volume (EELV). The parameter derived from the PV loop was the maximal volume difference between the inspiratory and the expiratory limbs of the PV loop at a given pressure, indicating the maximal hysteresis area. This was expressed as a ratio of the total lung capacity, measured as the volume gained on the PV loop at $4 \mathrm{kPa}$ airway pressure. Furthermore, they hypothesized that the volume difference between the inspiratory and expiratory limbs of the PV curve at a given pressure would correspond to the change in EELV after the LRM at the same pressure. Both hypotheses were validated in their well controlled experimental study design. Specifically, a maximal hysteresis/ total lung capacity ratio of 0.3 predicted improvement in Crs, EELV and gas exchange after the LRM.

This easily applicable method provides a means to predict the potential for recruitment, which is of paramount importance to recruitment strategies in acute lung injury [2]. However, we do not have any convincing evidence that recruitment strategies improve clinical outcomes of patients with acute lung injury (ALI)/acute respiratory distress syndrome (ARDS) [3-5], although many physiological studies could demonstrate a recruitment-induced increase in Crs, EELV and gas exchange (see $[3,6]$ ). Recruitment of lung volume is critical in ALI/ARDS, in which loss of aerated lung volume is an important pathophysiological factor that leads to intrapulmonary shunting of blood, culminating in severe hypoxaemia [7]. Consequently, the effect of recruitment in the clinical setting is mostly assessed by determining the effect on gas exchange. However, computed tomography (CT) studies $[5,8]$ indicate that dissociation between mechanical effects and the gas exchange effect of LRM can occur, rendering gas exchange a rather insensitive parameter with which to assess LRM. The reason for this dissociation is that gas exchange only improves when ventilation/perfusion ratios are affected concomitantly; specifically, ventilation must improve and perfusion must not diminish. However, because LRM might also have effects on the perfusion site, gas exchange merely reflects the functional effect of recruitment,

$\mathrm{ALI}=$ acute lung injury; $\mathrm{ARDS}=$ acute respiratory distress syndrome; $\mathrm{EELV}=$ end-expiratory lung volume; $\mathrm{Crs}=$ respiratory system compliance; $\mathrm{CT}=$ computed tomography; LRM = lung recruitment manoeuvre; $\mathrm{PV}=$ pressure-volume. 
whereas lung mechanics or CT analysis might reflect anatomical changes brought about by the LRM [5]. CT analysis may therefore be helpful in identifying the potential for recruitment as well as for assessing anatomical effects on lung ventilation. However, clinically, it is not practical to conduct repeated CT analyses in patients with severe ARDS patients in order to optimize the ventilator settings or guide a recruitment strategy.

Hence, the observation that routine, detailed analysis of a single PV loop might be helpful in predicting the anatomical effect of a LRM is of great interest. It is consistent with the finding that analysis of lung mechanics might be more accurate than gas exchange in assessing the effect of LRM $[8,9]$, insofar as it emphasizes the effect on respiratory mechanical behaviour rather than functional results. It is important to appreciate this because many studies were required to teach us that achievement of optimal gas exchange is not necessarily associated with the best outcomes in patients.

How could the information provided by Koefeld-Nielsen and colleagues [1] be used clinically? Their method could be used as a diagnostic tool to determine potential for recruitment in individual patients, who could then be stratified as possible responders or nonresponders in a clinical study of a recruitment strategy that applies only to responders. This makes perfect sense because it is reasonable to assume that any potential evidence in favour of a recruitment strategy in ALI/ARDS, in terms of clinical outcomes, will only be found if responders are subjected to the manoeuvre. We would be able to enter into a strategy of testing ALI/ARDS therapies tailored to individual pathophysiological observations, rather then just randomizing large groups of patients who share only a rather unspecific diagnosis, namely ALI/ARDS as defined by gas exchange and radiographical criteria. I am absolutely convinced that this is the way to go for future studies in our field. Before doing so, however, the experimental observation made by Koefeld-Nielsen and colleagues [1] must be assessed clinically. Clinical conditions might weaken a signal that may be obvious in experimental settings. If the method presented proves to be sufficiently robust to reflect the effect of LRMs before they are actually applied, then this could be the basis for a larger clinical trial, in which it is used as a diagnostic tool to stratify patients before randomization. I look forward to seeing this work followed; I consider it the way to go.

\section{Competing interests}

The author declares that they have no competing interests.

\section{References}

1. Koefoed-Nielsen J, Nielsen ND, Kjaergaard AJ, Larsson A: Alveolar recruitme nt can be predicted from airway pressure-lung volume loops: an experimental study in a porcine acute lung injury model. Crit Care 2008, 12:R7.

2. Slutsky AS, Hudson LD: PEEP or no PEEP: lung recruitment may be the solution. $N$ Engl J Med 2006, 354:1839-1841.
3. Meade MO, Cook DJ, Guyatt GH, Slutsky AS, Arabi YM, Cooper DJ, Davies AR, Hand LE, Zhou Q, Thabane L, Austin P, Lapinsky S, Baxter A, Russell J, Skrobik Y, Ronco JJ, Stewart TE: Ventilation strategy using low tidal volumes, recruitment maneuvers, and high positive end-expiratory pressure for acute lung injury and acute respiratory distress syndrome: a randomized controlled trial. JAMA 2008, 299:637-645.

4. Mercat A, Richard JC, Vielle B, Jaber S, Osman D, Diehl JL, Lefrant JY, Prat G, Richecoeur J, Nieszkowska A, Gervais C, Baudot J, Bouadma L, Brochard L: Positive end-expiratory pressure setting in adults with acute lung injury and acute respiratory distress syndrome: a randomized controlled trial. JAMA 2008, 299:646-655.

5. Gattinoni L, Caironi P, Cressoni M, Chiumello D, Ranieri VM, Quintel M, Russo S, Patroniti N, Cornejo R, Bugedo G: Lung recruitment in patients with the acute respiratory distress syndrome. N Engl J Med 2006, 354:1775-1786.

6. Lapinsky SE, Mehta S: Bench-to-bedside review: recruitment and recruiting maneuvers. Crit Care 2005, 9:60-65.

7. Ware LB, Matthay MA: The acute respiratory distress syndrome. N Engl J Med 2000, 342:1334-1349.

8. Henzler D, Hochhausen N, Dembinski R, Orfao S, Rossaint R, Kuhlen R: Parameters derived from the pulmonary pressure volume curve, but not the pressure time curve, indicate recruitment in experimental lung injury. Anesth Analg 2007, 105:1072-1078.

9. Grasso S, Terragni P, Mascia L, Fanelli V, Quintel M, Herrmann P, Hedenstierna G, Slutsky AS, Ranieri VM: Airway pressure-time curve profile (stress index) detects tidal recruitment/hyperinflation in experimental acute lung injury. Crit Care Med 2004, 32:1018-1027. 